\title{
Central venous air embolism without a catheter
}

Karl A. Poterack MD, Anil Aggarwal MD

Venous air embolism is a well-recognized complication of central venous catheterization. Although previous reports have documented venous air embolism occurring in a number of ways, including during initial catheterization, when catheters crack or are disconnected, and after catheter removal, no reports mention the possibility of air embolism occurring when a guide wire without a catheter was in place. A patient is presented who displayed signs and symptoms of venous air embolism (tachypnoea, chest pain, and arterial hypoxaemia) during central venous catheter manipulation while a guide wire alone was in place. Pulse oximetry was used to detect hypoxaemia and suggest an aetiology for the patient's clinical symptoms. It is postulated that a previously described gasp reflex or some sort of sustained negative pressure manoeuvre caused venous air embolism around the guide wire and accounted for the patient's signs and symptoms. During central venous catheter placement, a high index of suspicion for venous air embolism should be maintained, pulse oximetry should be used, the skin entrance site should be kept covered by an occlusive dressing, and the patient should be positioned head-down.

L'embolie veineuse aérienne est une complication bien reconnue de la cathétérisation du système veineux central. Même si des rapports préalables ont documenté que l'embolie veineuse gazeuse peut survenir de différentes façons incluant lors de la cathétérisation initiale, lors d'un bris de cathéter ou lors de la disconnection des cathéters, ainsi qu'après l'extraction de cathéter, aucun rapport ne mentionne la possibilité d'embolie gazeuse quand la broche-guide sans cathéter est en place. Un patient qui a démontré des signes et symptômes d'embolie

\section{Key words}

EMBOLISM: air.

From the Department of Anesthesiology, Medical College of Wisconsin, and the Milwaukee County Medical Complex, Milwaukee, Wisconsin.

Address correspondence to: Dr. Karl A. Poterack. Department of Anesthesiology, Medical College of Wisconsin, MFRC, Room A1000, 8701 West Watertown Plank Road, Milwaukee, WI 53226.

Accepted for publication 3rd December, 1990. gazeuse veineuse (tachypnée, douleur thoracique, et désaturation artérielle) durant la manipulation d'un cathéter veineux central est présenté alors que la broche-guide seule était en place. L'oxymétrie de pouls fut utilisée afin de détecter l'hypoxémie et suggérer l'étiologie des symptômes cliniques du patient. On présume qu' une inspiration profonde réflexe ou une pression négative soutenue lors de la manoeuvre a occasionné l'embolie gazeuse autour de la broche-guide. Durant' installation d'un cathéter veineux central, on doit maintenir un haut degré de suspicion face à l'embolie gazeuse veineuse, l'oxymétrie de pouls doit être utilisée et le site d'entrée doit être recouvert par un pansement occlusif, le patient doit être en position de Trendelenburg.

Venous air embolism (VAE) is a well-recognized complication of central venous catheter insertion that is known to occur during venepuncture, while catheters are in place, and during or after their removal. ' Its sequelae, including paradoxical arterial air embolism, hypoxacmia, hypotension, and death, are well-known and reviewed elsewhere. ${ }^{2}$ Factors favouring its occurrence include the generation of negative pressure by deep inspiration, the head-up position, and hypovolaemia, while some open communication (open catheter, cracked tubing, etc.) between the venous system and the atmosphere is an absolute necessity. ${ }^{3}$

A patient is presented who developed signs and symptoms of VAE in a previously unreported fashion, while a guide wire, not a catheter, was in place.

\section{Case report}

A 32-yr-old male non-smoker who had sustained an open fracture of the left tibia five months previously was re-admitted to the orthopaedic service with osteomyelitis of the tibia. He had no previous history of cardiac, pulmonary, neurological, or endocrine disease. Irrigation and debridement were performed on three occasions, resulting in a large soft-tissue defect. He was then brought to the operating room for creation of a latissimus dorsi free flap and placement of an antibiotic pump. At this time, a 9.0 French double-lumen silicone central venous catheter was inserted via the right subclavian approach for 
venous access and monitoring. A postoperative chest radiograph demonstrated the tip of the catheter to be in the contralateral subclavian vein. Two days after surgery, an attempt was made to re-position the catheter into the right atrium.

The patient was brought to the preoperative holding area, placed supine, and his right chest was prepared with betadine. The ECG was recorded using five leads, and a blood pressure cuff was placed on the left arm. The patient was awake and cooperative; no sedation was administered. The proximal lumen of the catheter was clamped and a guide wire was passed through the distal lumen while continuous blood return was observed. The patient was not placed in the head down position because the continuous blood return through the distal lumen was considered to indicate that central venous pressure was too high to permit VAE. The catheter was then removed and the wire was left in situ. No bleeding from the skin exit site was noted with the guide wire alone in situ. Because of concern about the location of the wire, a supine chest radiograph was obtained at this time. While the film was being processed, the patient became tachypnoeic, anxious, and complained of dyspnoea and chest pain. His heart rate and blood pressure remained stable at 115 beats $\cdot \mathrm{min}^{-1}$ and $130 / 80 \mathrm{mmHg}$, respectively. Pulse oximetry, recorded from the right index finger revealed an oxyhaemoglobin saturation $\left(\mathrm{SpO}_{2}\right)$ of $83 \%$ while breathing room air. The pulse oximeter waveform was synchronous with the ECG at 115 beats $\cdot \mathrm{min}^{-1}$. The patient was given $100 \%$ oxygen by face mask, positioned head-down, and the guide wire exit site was occluded with a sterile gauze. The $\mathrm{SpO}_{2}$ increased to $99 \%$ with resolution of his symptoms. The chest radiograph revealed the tip of the wire to be in the contralateral subclavian vein, and further manipulations did not succeed in placing it in the right atrium. A new double-lumen catheter was inserted, and the patient was returned to the ward breathing oxygen. Follow-up examination the next day revealed no obvious sequelae. His $\mathrm{SpO}_{2}$ by pulse oximetry was $96 \%$ while breathing room air.

\section{Discussion}

The dyspnoea, chest pain, and arterial hypoxaemia experienced by this patient during central venous catheter manipulation strongly suggest VAE. Other possible causes include pulmonary emboli from venous thrombosis or from the catheter, acute pulmonary oedema, and pneumothorax. The lack of abnormal chest radiograph findings effectively rule out pneumothorax or pulmonary oedema. While pulmonary emboli from venous thrombosis cannot be ruled out by the chest radiograph findings, the rapidity of the development of the patient's signs and symptoms, their rapid resolution with oxygen and occlu- sion of the exit site and the absence of further sequelae are most consistent with VAE.

Previous reports have indicated that VAE associated with central venous catheterization most commonly occurs in three settings: (1) during insertion, especially when care is not taken to keep the catheter hub covered; (2) while catheters are in place, and become inadvertently disconnected; (3) after removal, especially with the patient in the head-up position, when a remaining fibrous tract provides a communication and air is introduced by negative pressure spontaneous ventilation. ${ }^{1.3 .4}$ Entrained air can enter a 16-gauge catheter at a rate of $20 \mathrm{ml} \cdot \mathrm{sec}^{-1}$ with a pressure gradient of $3.7 \mathrm{mmHg}$ and thus can cause cardiovascular collapse in ten seconds. ${ }^{5.6}$ Admittedly, this intrathoracic negative pressure gradient would be difficult to maintain except in cases of severe airway obstruction. However, Adornato et al. demonstrated a "gasp" reflex occurring in response to VAE. In their study of anaesthetized dogs given slow intravenous infusions of air, this reflex consisted of a short cough, followed by a brief expiration and then a forced inspiration ("gasp") that was held for several seconds. It occurred at an average threshold infusion rate of $0.36 \mathrm{ml} \cdot \mathrm{kg}^{-1} \cdot \mathrm{min}^{-1}$ and made central venous pressure abruptly negative (by an average of $1.2-1.5 \mathrm{mmHg}$ ) for long enough to cause further embolization of air leading to the death of the animal if there was still an open venous-atmospheric communication. The administration of nebulized cocaine via an endotracheal tube blocked the response, whereas iv cocaine did not. This led the authors to conclude that this reflex was mediated by receptors in the lung. ${ }^{7}$ In addition, the administration of a sub-lethal bolus of air did not provoke this response. Underwater necropsy findings showed air in the right heart after a fatal VAE by bolus while showing air dispersed throughout the pulmonary circulation after a VAE by slow infusion. This gasp reflex and the resultant negative intrathoracic pressure may be the mechanism for cardiovascular collapse in spontaneously breathing and/or recumbent patients. In our patient, a sustained negative pressure manoeuvre likely occurred while the guide wire was in place, since continuous blood return from the distal lumen was noted while the catheter was in place.

Several previous reports have documented the usefulness of changes in arterial oxygenation as a marker of significant VAE. Glenski and Cucchiara have shown that decreased transcutaneous $\mathrm{PO}_{2}$ is a more sensitive indicator of VAE than decreased $\mathrm{PETCO}_{2}$ in neurosurgical patients. ${ }^{8}$ A recent study in which the lungs of sheep were ventilated with $33 \%$ oxygen demonstrated a decrease in arterial $\mathrm{PO}_{2}$ from an average of $152 \mathrm{mmHg}$ to $92 \mathrm{mmHg}$ after the slow iv injection of $100 \mathrm{ml}$ of air. At the same time, $\mathrm{PETCO}_{2}$ decreased from $34 \mathrm{mmHg}$ to $30 \mathrm{mmHg}$. $^{9}$ 
Because the experience of most anaesthetists with VAE involves neurosurgical patients in whom the trachea is already intubated and the lungs are artificially ventilated with $33-100 \%$ oxygen, it is not surprising that the literature has focused on precordial Doppler, $\mathrm{PETCO}$, or trans-oesophageal echocardiography to detect intravenous air. However, it is clear that oxyhaemoglobin desaturation from VAE can occur in the presence of modest changes in $\mathrm{PETCO}_{2}$. Pulse oximetry would be most useful for the detection of air emboli in the patient breathing room air.

Finally, the rationale for attempting to reposition the central venous catheter should be mentioned. Catheter tip positions in other than the right atrium or superior vena cava have been associated with an increased risk of a number of complications, including thrombophlebitis, vessel perforation, and fallacious CVP readings. ${ }^{10} \mathrm{Be}$ cause of this, it has been the usual practice at our institution to attempt to place catheters intended for longterm use into the right atrium or superior vena cava.

To our knowledge, this is the first case of VAE reported while a guide wire but not a catheter was in place. The rapid availability of pulse oximetry confirmed the seriousness and probable aetiology of the patient's complaints. It is suggested that when placing central venous catheters, the skin entrance site should be kept covered by a gauze or other occlusive dressing if a guide wire is left in place, the patient be kept in the head-down position, and that pulse oximetry should be used to detect or confirm suspected VAE.

\section{References}

I Kashuk JL, Penn 1. Air embolism after central venous catheterization. Surg Gynecol Obstet 1984; 159: 249-52.

2 Shapiro $H M$. Neurosurgical anesthesia and intracranial hypertension. I $n$ : Miller RD (Ed.). Anesthesia. New York: Churchill Livingstone, 1986; 1580-1.

3 Lambert MJ. Air embolism in central venous catheterization. South Med J 1982; 75: 1189-91.

4 Feliciano DV, Mattox KL, Graham JM et al. Major complications of percutaneous subclavian venous catheterization. Am J Surg 1979; 138: 869-74.

5 Lippman M. Air embolism. Int Anesthesiol Clin 1972; 10: 93-9.

6 Ordway $C B$. Air embolus via CVP catheter without positive pressure: presentation of case and review. Ann Surg 1974; 179: 479-81.

7 Adornato DC, Gildenberg PL, Ferrario CM et al. Pathophysiology of intravenous air embolism in dogs. Anesthesiology 1978; 49: 120-7.
8 Glenski JA, Cucchiara RF. Transcutancous $\mathrm{O}_{2}$ and $\mathrm{CO}_{2}$ monitoring of neurosurgical patients: detection of air cmbolism. Anesthesiology 1986; 64: 546-50

9 Pfitazner J, Petito SP, MCLean AG. Hypoxaemia following sustained low-volume venous air cmbolism in shecp. Anaesth Intensivc Care 1988; 16: 164-70.

10 Dunbar RD, Mitchell R, Lavine $M$. Aberrant locations of central venous catheters. Lancet 1981; 1: 711-4. 